\title{
Humanitarian framework of modern pedagogical education in Russia
}

\author{
Marina Siraeva $^{1}$ \\ $\mathrm{PhD}$, Associate Professor, Institute of Language and Literature, Udmurt State University, Izhevsk city, \\ Russian Federation
}

\begin{abstract}
The goal of the paper is to review and classify current trends and outcomes of modern pedagogical education in Russia on the back of humanitarization of higher education as well as to justify principles of humanitarization of higher education content. The relevance of this subject stems from current shifts of socio-economic environment in Russia, which have brought new humanitarian paradigms to the forefront. The authors examine pedagogical process as a humanitarian phenomenon pursuing the aim to specify the goals and objectives of modern pedagogical education. The article highlights current demand to develop and promote pedagogical tools of humanitarian training as a model based on cultural practices which consequently implies structuring of the education content and process according to a person's nature, mind and spirit, contributing to the integrity of a human's inner world and the development of a whole person.
\end{abstract}

\section{Introduction}

Higher education management is the subject of policy debate and public discourse at both the national and supra-national levels. The OECD, UNESCO, and EU, alongside other international organizations and national governments, continually emphasize the significance of higher education for economic growth and social well-being, and especially as an antidote to the impact of the global challenges. The performance and quality of higher education has become an index of a country's capacity to lay foundation for its social and economic advances [1].

Understanding the changes that have taken place in the global higher education in the past half century is rather challenging due to the scope and complexity of those trends. One can, without risk of exaggeration, speak of an academic "revolution" - a series of transformations that have affected most aspects of postsecondary education worldwide. However, comprehending a dynamic process while it is taking place is not an easy task. Arguably, the developments of the recent past are at least as dramatic as those in the 19th century when the research university evolved, first in Germany and then elsewhere, and these developments fundamentally changed the nature of the university worldwide. The academic changes of the late $\mathrm{XX}^{\text {th }}$ and early $\mathrm{XXI}^{\text {st }}$ centuries are more extensive in that they are truly global and affect many more institutions and larger populations [2].

Experts assert that there are three main trends in the development of higher education: internationalization, globalization, and Europeanization. Internationalization tends to address an

\footnotetext{
${ }^{1}$ Corresponding author: marinasiraeva@mail.ru
} 
increase in cross-border learning activities. It is often analyzed in relation to student mobility and academic cooperation. Globalization suggests that borders and national education systems as such are blurred, and is frequently associated with competition and commercial knowledgetransfer. Europeanization is the regionally oriented version of either internationalization or globalization and is often analyzed in respect of cooperation and [1].

What used to be a centralized and unified system of education is gradually being replaced by a system that tries to accommodate the diverse interests of students, the academic community and employers to a larger extent by allowing greater academic freedom and institutional autonomy and requires mutually beneficial coexistence and cooperation of various cultures [3].

Nowadays culture is related to basic results of human thinking and activity, as an integrated "civilized" space that covers. Thus culture implies social experience, patterns and standards that are to shape and specify peculiar attitudes of a society to everything that is interpreted as something new / unknown and different. Taking this into account we may assume that axiological issues (apart from intercultural predominance) are becoming rather crucial. Intercultural component is a challenge that makes us expand educational process in order to provide opportunities for real and effective intercultural interaction and communication for students of modern universities. Traditional borders are being extended, or, to put in a positive way, are opened up for fresh innovative perspectives.

Our society today needs young people who are flexible, creative, and proactive - young people who are able to solve problems, take decisions, think critically, generate ideas effectively and work efficiently within different teams and groups. The "knowing of knowledge" is no longer enough to succeed in the increasingly complex, fluid, and rapidly evolving world in which we live. In order to optimize life-long learning and potential success it is now widely accepted that young people need to have opportunities to develop personal capabilities and effective thinking skills as part of their well-rounded education. An establishment of higher education as a significant social institute reflects the development tendencies and condition of the society. Changes in the system of public relations actively affect education, require mobile and adequate answers for the challenges brought forward in the new stage of the historical development [4].

\section{Current trends in modern system of higher education in Russia. Humanitarization of higher education}

The system of higher education in Russia has undergone several thorough reforms since the early 1990s. The reforms were based on the 1992 Education Act and 1996 amendments and changes reflected in the Higher Education and Postgraduate Education Act.

A range of research proves that contemporary higher education in Russia requires new claims with reference to global transformations, transparency, cultural diversity.

Relying on the analysis of current models reflected in the system of modern Russian higher education we can summarize a range of features attributed to contemporary higher education in Russia including:

- continuity;

- diversity;

- fundamentality;

- integrity;

- humanitarization;

- humanization;

- democatization;

- computerization;

- correlations with science and manufacture. 
The goal of the paper is to review and classify current trends and outcomes of modern pedagogical education in Russia on the back of humanitarization of higher education as well as to justify principles of humanitarization of higher education content. The relevance of this subject stems from current shifts of socio-economic environment in Russia, which have brought new humanitarian paradigms to the forefront.

Taking into account distinctive features of Russian system of education within the framework of our research pedagogical process is regarded as a humanitarian phenomenon pursuing the aim to specify the goals and objectives of modern pedagogical education. Processes of globalization and integration of the modern educational environment highlight the urgency to develop and promote pedagogical tools of humanitarian training as a model based on cultural practices which consequently implies structuring of the education content and process according to a person's nature, mind and spirit, contributing to the integrity of a human's inner world and the development of a whole person.

The humanitarization of higher education content presupposes certain shifts in all its components including goals, content, methods, models, technologies. According to A.M. Novikov (1998), the humanitarization of education should be considered "in the broadest sense as the process of shaping a distinctive, appropriate humane attitude to the world".

Thus, humanitarization could be seen "as a way to stick a young person to the spiritual values of the civilized world, as his cultivation in the broad sense of the word, which is not restricted by pure professionalization"as an update of the means for improving cultural competences and enriching humanitarian activities of modern universities [5]. Modern pedagogics declares humanitarization as an integral part of the university environment and finds it crucial to increase a share of humanitarian disciplines in the teaching process. Meanwhile, according to modern standards of higher education humanitarian unit makes up about a quarter of the total hourly academic load in the University [6, 7]. In this regard, modern higher education could apply a number of tools to intensify its humanitarian background:

1. Advanced studies courses, special courses, research activities of students, extracurricular activities (clubs, excursions, studio classes, weekend lectures, etc.) [8-10];

2. Enrichment of the cultural context of modern universities. Obviously, the real content of the learning process should not be restricted by some fragmentary academic qualifications; the phenomena of the youth subculture should be taken into account in the educational process, the objective assessment of which is an important task of the teaching staff of the university, and the university humanitarian background should be capitalized on personal experience of students and teachers [11]

The relevance of humanitarian frameworks is due to the shifts of socio-economic conditions in Russia, which have brought new humanitarian paradigms to the forefront.

The interaction of the processes of humanization and humanitarization of education is based on the fact that the notion "humanitarization" includes both proper humanitarian knowledge embracing all the sciences relevant to human beings as well as literature and art and education based on humanism, maintaining the ethics of humanism expressed in the values of the mankind.

Humanitarization could be regarded as a strategic penetration of cultural practices into the content of education aimed at strengthening and accelerating students' personal growth.

Humanization of education demands shifts in educational activity and clear references to common values and improvement of relationships between a personality and the society.

The comparative analysis of the concepts "humanization of education" and "humanitarization of education" gives us an opportunity to come to a conclusion that "humanization of education" means creation of the humane social system of education within a society which corresponds to the values and ideals of humanism while "humanitarization of education" is connected with the teaching methodology in a higher educational institution, with the reorientation of the basic and elective disciplines aligning with sociocultural backgrounds. 
In practical terms it seems crucial to provide appropriate means of interaction between regional social and economic space and universities. The interaction mentioned above is supposed to provide preferable social, economic and scientific mobility of the region.

The dissolution of the Soviet Union and the transition toward democracy had a profound effect on national education policy. In 1992 a reform philosophy was set forth in the Law on Education. The fundamental principle of that law was the removal of state control from education policy [12].

\section{Regionalization of higher education. Club activities as a tool of humanitarization of higher education}

In regions with non-Russian populations, this meant that educational institutions could base their curricula and teaching methods on national and historical traditions. In all regions, enactment of the law meant significant autonomy for local authorities to choose the education strategies most appropriate to the time and place. Post-Soviet education reform also stressed teaching objectively. It aimed at discarding all forms of the narrow, institutional view that had dominated the previous era and attempted, by presenting a broader interpretation of the world, to prepare young people to deal with all aspects of the society they would encounter. The new vision of education was more focused the arts, humanities and social sciences.

Nowadays regional Universities are regarded as social phenomena with inherent duality: as "manufacturing organizations" established to develop and implement educational products (scientific and educational goods and services) and as a subject of humanitarian, social and cultural development of regions.

We believe that in this respect the experience of Udmurt State University (Izhevsk city, Russia) as a regional institution aimed at extending and diversifying its humanitarian environment could be rather relevant. Thus the University mentioned above has been applying and facilitating new learning resources, namely club activities as a part of extracurricular education.

It should be noted that humanitarian facilities of Universities Clubs were highly appreciated and promoted in the Soviet higher education.

One of the fields to realize humanitarian dimension in language learning were International Friendships Clubs (IFCs, known as KID or "Interclubs" in Soviet Russia).

They were organized to strengthen links between socialist countries and to expand students' international, patriotic and communicative competences. Every school and Young Pioneer Palace was supposed to have at least one Club alike, applied as a tool of international and interethnic education of young people. As it had been initially claimed IFC's goal was to promote cultural awareness, respect, and understanding among all students through various mutually beneficial cultural, educational, and social activities and enterprises and as well as to advocate and promote the concept of international solidarity and friendship. Meanwhile actual contacts outside of officially approved exchanges were restricted and Soviet citizens found it almost impossible to travel abroad. The Soviet authorities did give scholarships to Third World students so they could study in Soviet Universities. In a broad sense IFCs pursued the idea of the comprehensive fraternal cooperation and mutual aid of the peoples and nations that have embarked on the socialist path of development.

If we focus on the role of IFCs as a component of humanitarian and international education, it should be pointed out in this regard that those clubs were coordinated by teaching stuff through counseling and tutoring, while students were encouraged to show the initiative and develop their practical and organizing skills. Basically IFC's activities were coordinated and organized by its Board headed by the President. The Board elected by General Assembly was under the control of All-Union Leninist Young Communist League (VLKSM) in cooperation with Pioneer Brigades. IFC structure was made up of a number of sections. The section of 
international correspondence was regarded as one of the key elements of IFC. Students involved in the club activities were given a good opportunity to find penpals in countries like German Democratic Republic, Czechoslovakia, Bulgaria, Poland, Hungary, Romania, etc. Moreover correspondence with foreign peers was a good resource to improve language skills, communicative competences and cultural awareness. Moreover afterwards those letters were used as subjects for discussion in foreign language classes; above that the letters were regarded as a part of educational content to practice grammar and lexical patterns and to expand crosscultural competences.

Taking this concept into consideration in 2005 we organized students' linguistic club in our Udmurt State University. The starting point was the idea that beneficial combination of both formal and non-formal education is supposed to have a certain impact on students' cultural and humanitarian awareness, their personal and professional development and their successful adaptation to multicultural reality.

The research was based on the following concept: to encourage students to take part in a linguistic club founded on principles of non-formal education (such as voluntariness, subjectivity, freedom, choice, personal interest) and theoretical background of multicultural education (openness, dialogue of different cultural areas, value judgment and tolerance towards cultural pluralism, availability for interpersonal and intercultural contacts).

The content of the given linguistic club was made up of applying to culturally relevant texts, watching and discussion of films; meetings with foreign guests and teachers, interaction with students from other countries via Internet, implementation of some Information Technologies.

Based on the concept of multicultural education a students' linguistic club being a part of non-formal education is supposed to carry out a number of certain functions within University educational area such as linguistic; cognitive and educational.

Linguistic function within club activities means that participants are given opportunities to master a linguistic competence (that is to say to use lexical, grammatical and phonetic resources of the language adequately and accurately).

Cognitive function is reflected in certain activities to encourage personal cultural standards and level of multicultural competence. Linguistic club encourages students to get involved in a definite sociocultural space, in cultural and history backgrounds of certain peoples, and obviously, in their native culture and history.

Educational function assumes that students are involved in culturally relevant activities. That is supposed to encourage them not only to get rid of language barrier but to add to their cultural standards.

The humanitarian paradigm within the linguistic club was realized through:

- folklore and mythology and interaction with artifacts of cultural diversity and multiculturalism (transcendental paradigm);

- extra knowledge (apart from fundamental knowledge) about different cultures and restructuring of any acquired knowledge through the humanitarian and intercutural points of view (technocratic paradigm);

- students interactions with representatives of different cultures in lessons and involvement inhumanitarian activities in wide social reality (humanitarian paradigm).

\section{Conclusion}

Thus humanitarian education within student's linguistic club is expected to provide students with educational experiences that enable them to maintain commitments to their community cultures as well as acquire certain competences, skills, and cultural experience needed to function in the national civic culture and community, to function effectively within and across diverse groups and beliefs. 
It is possible to identify a range of measures that could contribute to the development of humanitarian framework of modern pedagogical education in Russia.

Firstly, the government must focus its efforts on regaining equilibrium between humanitarian and natural scientific knowledge.

Secondly, in order to provide high standards of higher education, schooling should provide students with the tools to develop their humanitarian competences.

Thirdly, close interaction and collaboration of academic institutions with public bodies, businesses and non-governmental organizations. These efforts could include schemes to share experience and exchange staff, and the establishment of specialized departments.

\section{References}

1. Higher education in the EU: approaches, issues and trends (2015)

2. P.G. Altbach, L. Reisberg, L.E. Rumbley Trends in Global Higher Education UNESCO Publishing, 48 p. (2010)

3. The System of Education in Russia: Nordic Recognition Network (NORRIC), 66 p. (2005)

4. I. Kulisha Humanitarization of education as a development factor of professional culture for future hospitality specialists. Problems of education in the XXIst century, Vol 8. (2008)

5. A.S. Kravets Reflections on the teaching of philosophy. Bulletin of the VSU, 1, 102-115 (1996)

6. R. Gaisin, S. Beketova, E. Vlasova, G. Sharapova, Humanitarization of geographic education in universities. Mediterranean Journal of Social Sciences, 1(3), 131-135 (2015)

7. V.I. Gorovaya, Ulyaev, S.I. Humanization of education and professional culture of a specialist. Moscow: Narodnoye obrazovaniye (2004)

8. J. Cai, V.T. Youngblood, E.A. Khodyreva, A.N. Khuziakhmetov Higher Education Curricula Designing on the Basis of the Regional Labour Market Demands. EURASIA Journal of Mathematics, Science and Technology Education, 13(7), 2805-2819 (2017)

9. A.A. Galushkin Organizations of the sphere of education and science methods of competitiveness improvement. European Research Studies Journal, 20(4B), 421-431 (2017)

10. A.R. Masalimova, E.Y. Levina, R.I. Platonova, K.Yu Yakubenko, N.V. Mamitova, L.L. Arzumanova, V.V. Grebennikov, N.N. Marchuk Cognitive Simulation as Integrated Innovative Technology in Teaching of Social and Humanitarian Disciplines. EURASIA Journal of Mathematics, Science and Technology Education, 13(8), 4915-4928 (2017)

11. V.A. Kozyrev Building a model of humanitarian educational environment. Teacher: science, technology, practice, 7, 26-32 (1999)

12. International Education Guide: For the Assessment of Education from the former USSR and the Russian federation: Government of Alberta, International Qualifications Assessment Service (IQAS), 120 p. (2016) 